Louisiana State University

LSU Digital Commons

Faculty Publications

Department of Biological Sciences

$5-1-2006$

\title{
Aversive parenting in China: Associations with child physical and relational aggression
}

\author{
David A. Nelson \\ Brigham Young University \\ Craig H. Hart \\ Brigham Young University \\ Chongming Yang \\ Brigham Young University \\ Joseph A. Olsen \\ Brigham Young University \\ Shenghua Jin \\ Beijing Normal University
}

Follow this and additional works at: https://digitalcommons.Isu.edu/biosci_pubs

\section{Recommended Citation}

Nelson, D., Hart, C., Yang, C., Olsen, J., \& Jin, S. (2006). Aversive parenting in China: Associations with child physical and relational aggression. Child Development, 77 (3), 554-572. https://doi.org/10.1111/ j.1467-8624.2006.00890.x

This Article is brought to you for free and open access by the Department of Biological Sciences at LSU Digital Commons. It has been accepted for inclusion in Faculty Publications by an authorized administrator of LSU Digital Commons. For more information, please contact ir@lsu.edu. 


\title{
Aversive Parenting in China: Associations With Child Physical and Relational Aggression
}

\author{
David A. Nelson, Craig H. Hart, \\ Chongming Yang, and Joseph A. Olsen \\ Brigham Young University
}

\author{
Shenghua Jin \\ Beijing Normal University
}

\begin{abstract}
This study assessed the combined and differential contributions of Chinese mothers and fathers (in terms of spouse-reported physically coercive and psychologically controlling parenting) to the development of peerreported physical and relational aggression in their preschool-age children (mean age of 5 years). Results of the two-group (boys and girls) latent sum and difference structural equation model showed that combined parenting effects were slightly more prevalent than differential effects in predicting aggression. Furthermore, physical coercion was predictive of aggression in boys whereas psychological control was primarily associated with aggression in girls. Findings extend our understanding of relational aggression and the meaning of aversive parenting, particularly within the Chinese cultural context.
\end{abstract}

For the past several decades, social science researchers have been interested in examining the effects of specific parenting styles and practices on various child outcomes (e.g., Maccoby \& Martin, 1983; Peterson \& Hann, 1999). This approach has made important contributions to our understanding of the development of specific child behaviors such as aggression. In particular, research to date has provided sufficient evidence of differences in parenting and family factors between homes of aggressive and nonaggressive children (see Coie \& Dodge, 1998, for a review). In particular, coercive and psychologically controlling parenting has been consistently found to be a predictor of children's aggressive behavior patterns with peers (Hart, Newell, \& Olsen, 2003; Nelson \& Crick, 2002). Attention to the effects of these parenting styles and practices has gradually expanded to include parenting in diverse non-Western cultures.

Funding for this study was provided by the College of Family, Home, and Social Sciences, the Camilla Eyring Kimball Endowment, the BYU Family Studies Center, and the Zina Young Williams Card Professorship awarded to Craig H. Hart. Special thanks are extended to J. Noelle Scott McDowell, whose honors thesis provided the impetus for this study. Portions of this paper were presented in C. S. L. Cheah and S. Y. Park (Chairs), An examination of parenting beliefs and practices in China and South Korea at the XVIIIth biennial meetings of the International Society for the Study of Behavioural Development, held in Ghent, Belgium (July 2004).

Chongming Yang is now at the Social Science Research Institute, Duke University.

Correspondence concerning this article should be addressed to David Nelson, School of Family Life, Brigham Young University, 2102C JFSB, Provo, UT 84602-6720. Electronic mail may be sent to david_nelson@byu.edu.
One research focus has compared Western parenting practices with central features in Chinese parenting. Specifically, researchers have debated on whether parental control can be similarly defined and, by extension, whether it is associated with comparable child outcomes for Chinese and North American cultures (Chao, 1994; Chao \& Tseng, 2002; Chen, Liu, \& Li, 2000; Grusec, 2002; Lau \& Yeung, 1996; Wu et al., 2002). Accordingly, one of the primary aims of the present study is to expand research in this domain by further defining and assessing the correlates of controlling parenting for a sample of mainland Chinese preschoolers. In particular, associations of aversive parenting (physical coercion and psychological control) with aggression subtypes (physical and relational) are assessed. This research emphasis is significant given previous studies showing that aggression is associated with peer acceptance difficulties in China, as in other cultures (Chen, Dong, \& Zhou, 1997; Chen \& Rubin, 1992; Chen, Rubin, \& Li, 1995; Chen, Rubin, \& Sun, 1992; Crick et al., 1999).

A second important aim is to expand on previous research that intends to measure the relative contributions of mothers versus fathers in their parenting influence. Given limitations of previous studies regarding maternal and paternal influence, we implement a novel statistical approach to better address the potential combined and differential contributions of mothers and fathers in predicting child aggression. The model also allows us to explore unique associations between parenting dimensions and

(C) 2006 by the Society for Research in Child Development, Inc. All rights reserved. 0009-3920/2006/7703-0005 
aggression subtypes. We discuss the findings in the context of recent research regarding parenting influence in Chinese culture.

\section{Chinese Parenting and Child Outcomes: The Meaning of Control}

As researchers have begun to explore child development and its correlates within Asian societies, lively debates regarding the Asian child's experience of parenting have emerged. Among the most interesting discussions in the literature has been the definition and meaning of parental control among Chinese parents (Sorkhabi, 2005). Research has underscored one of two contrasting positions on this issue, consistent with a larger debate on possible variation across cultures in developmental processes (i.e., different patterns of covariance among variables across cultures; Rowe, Vazsonyi, \& Flannery, 1994). The first position is a unique-process view regarding cultural differences in parenting and child correlates, essentially espousing the belief that parental control may differ by culture in its effects on child outcomes (Chao, 1994, 2001; Chao \& Tseng, 2002; DeaterDeckard \& Dodge, 1997; Wu, 1981). Thus, the psychological processes inherent in child socialization may have qualitatively different meanings in China.

In particular, Ruth Chao (1994), in studying immigrant Chinese families, has asserted that parental control among Asians should be defined on the basis of indigenous notions rather than on conceptions imposed by Western parenting constructs. In particular, Chao has taken issue with the characterization of Asian parents as harsh, restrictive, and domineering, characteristics commonly associated with Baumrind's conception of authoritarian parenting. Indeed, observers have noted and comparative studies have consistently shown Chinese parents to be more physically coercive, restrictive, and controlling in their parenting styles when compared with North American parents (Chiu, 1987; Dornbusch, Ritter, Leiderman, Roberts, \& Fraleigh, 1987; Ho, 1986; Hsu, 1985; Leung, Lau, \& Lam, 1998; Porter et al., 2005; Wu et al., 2002). Chao argued that an alternative (indigenous) parenting style referred to as chiao shun ("training") better addresses positive developmental trends in Chinese children. Chiao shun is an outgrowth of the Chinese indigenous notion of parental control referred to as guan, which implies a form of parental governing that is demonstrative of involvement and concern. This form of parental control was offered as an explanation for the seemingly paradoxical finding in studies that authoritarian parenting, although commonly associ- ated with poor school achievement in European Americans, did not appear to hamper Asian students' academic progress (e.g., Dornbusch et al., 1987). Accordingly, this type of control is hypothesized to be favorable rather than damaging to children's development, as Chinese children may view it as a natural extension of high parental expectations (Chao \& Sue, 1996).

An alternative explanation for this paradox is that parental influence may play little role in Asian children's academic outcomes, as negative effects of authoritarian parenting may be outweighed by a peer environment in which a fear of academic failure promotes strong academic motivation (Steinberg, Dornbusch, \& Brown, 1992). But Chao (1994) refutes this assertion, stating that, "... this paradox may be explained by the fact that the parenting concepts 'authoritarian' and 'restrictive' are not very relevant for Asians, although they may be important for understanding European-American parenting ... For Asians, parental obedience and some aspects of strictness may be equated with parental concern, caring, or involvement" (p. 1112). Accordingly, the notion of "training" is offered to take perceptions of Chinese parenting beyond the authoritarian parenting style. This idea has influenced how conceptions of authoritarian parenting are presented (e.g., Baumrind, 1996; Grusec, 2002; Russell, Mize, \& Bissaker, 2002).

However, there are a number of reasons as to why this judgment may need to be revisited. First, Chao's reformulation is based on studies such as that of Dornbusch et al. (1987), who predominantly measured authoritarian parenting with an emphasis on parental desire for children's unquestioning obedience (nondemocratic control) as well as non-reasoning-oriented demands. Although these are important aspects of authoritarian control, they may provide an incomplete conceptualization. As noted by Chao (1994), the notions of chiao shun and guan, demonstrative of parental support, care, and concern, are hardly consistent with the general view of authoritarian parenting, which is commonly defined by the degree of parental hostility and rejection toward the child (a lack of warmth and support). Furthermore, other elements of authoritarian parenting include physical and verbal coercion (Yang et al., 2004), which go well beyond notions of nondemocratic control. In our minds, the concepts of chiao shun and guan may actually be more closely aligned with conceptions of authoritative parenting (cf. Baumrind, 1996). The traditional definition of authoritative parenting (Baumrind, 1971) combines high demands, firm control, democratic participation, induction, and warmth. "Training" on the part 
of Chinese parents, if their children do perceive it in the context of a caring, concerned relationship, would appear more consistent with authoritativeness. The cultural variation on this theme would be that Chinese parents are more likely to endorse unquestioning obedience, thereby reflecting less emphasis on democratic participation (cf. Wu et al., 2002). Yet firm control remains in league with warmth and support, according to Chao (1994). Consistent with these ideas, mainland Chinese parenting practices and values have been shown to correlate with both authoritative and authoritarian parenting styles (Wu et al., 2002; Xu et al., 2005).

Darling and Steinberg's (1993) distinction between parenting styles and practices also underscores our contention. In essence, whereas specific parenting practices may vary across cultures (e.g., emphasis on unquestioning obedience), the overall style may be similar (e.g., Wu et al., 2002). Specifically, parenting style represents the emotional climate of the parent-child relationship, communicating how the parent feels about the child rather than the child's behavior per se (Darling \& Steinberg, 1993; Grusec, 2002). Thus, authoritarian parenting is a style in which the overall emotional climate is typically described as one of rejection (predominantly reflected by a lack of warmth and support). In contrast, Chinese children presumably interpret chiao shun and guan as a sign of parental involvement and caring concern. Accordingly, behaviors more consistent with the rejecting emotional climate of the authoritarian style (e.g., excessive physical discipline) would be expected to produce negative outcomes, regardless of culture, if children perceive they are being rejected (cf. DeaterDeckard \& Dodge, 1997; Khaleque \& Rohner, 2002).

Thus, Chao's notion of training among Chinese parents, if it can be conceptualized as authoritarian parenting, seems representative of relatively mild forms of authoritarian parenting. In contrast, a number of more recent studies suggest that the authoritarian style, when encompassing behaviors reflecting parental rejection, has predictable negative consequences for Chinese children. These studies are consistent with the second position on the control debate, which comprises a common-process view of child socialization, in which child outcomes related to perceived aversive forms of parental control are presumed to be essentially universal across cultures (see Lansford et al., 2005; Nelson, Nelson, Hart, Yang, \& Jin, 2006, for recent reviews). Consistent with this view, Chinese adolescents and adults view dominating parental control (i.e., parents who are angry, restrictive, and deny child independence) as adverse and it is cited as a source of significant re- sentment and conflict (Lau \& Cheung, 1987; Lau, Lew, Hau, Cheung, \& Berndt, 1990; Lau \& Yeung, 1996). Accordingly, a substantial number of recent studies expectedly demonstrate that authoritarian (harsh, power assertive) parenting in Chinese culture is associated with children's externalizing (aggressive/ disruptive) behaviors (Chang, Lansford, Schwartz, \& Farver, 2004; Chang, Schwartz, Dodge, \& McBrideChang, 2003; Chen et al., 1997; Chen, Wang, Chen, \& Liu, 2002; Chen, Wu, Chen, Wang, \& Cen, 2001; Yang et al., 2004).

Chen et al. (1997) have also demonstrated with a Beijing sample that harsh authoritarian parenting (including physical punishment) was negatively associated with academic achievement. These findings further refine the distinction between Chao's notion of parental training (consistent with mild forms of parental control) and truly aversive forms of authoritarian control among Chinese parents. Given these recent findings, it is apparent that Western definitions of authoritarian parenting appear relevant in describing, in part, the nature of socialization in Chinese households, and negative child outcomes are expected from a common-process point of view when parents communicate parental rejection with harsh authoritarian practices. In contrast, Chao's (1994) conceptualization of "training" may be more valuable in describing associations between less harsh forms of Chinese parental control and child outcomes. Chao and Tseng (2002) have recently acknowledged this trend in the literature, stating, "... the effects of control on child well-being for Asians appear to depend on the way control is defined such that indigenous notions have positive effects and a domineering control primarily has negative effects among groups of Asian and European descent" (p. 77). This study does not consider indigenous forms of Chinese parenting but seeks to further demonstrate that aversive forms of controlling parenting (i.e., excessive physical punishment) are associated with aggression in Chinese preschoolers.

\section{Beyond Behavioral Control: Psychological Control in Chinese Parenting}

The above debate over the meaning of control is also limited in that it has focused on behavioral control to the exclusion of psychological control. Psychologically controlling parenting is defined as a negative parenting style that is focused on restricting children's emotional and psychological autonomy (Barber, 1996), and a limited number of studies show that it also has relevance to Chinese parenting. Compared with their North American counterparts, 
Chinese mothers report using more "love-oriented" methods of discipline, such as the use of love withdrawal when a child misbehaves (Ho, 1986). In addition, Chinese parenting is characterized by other features consistent with the notion of psychological control, such as shaming behaviors, threats of abandonment, and derogatory comments (Fung, 1999). Chinese mothers apparently use this control tactic more frequently than North American mothers (Wu et al., 2002). Furthermore, a couple of studies have found psychologically controlling parenting to be associated with externalizing and internalizing difficulties in Chinese preschoolers (Nelson, Hart, $\mathrm{Wu}$, \& Olsen, in press; Olsen et al., 2002; Yang et al., 2004). These studies further underscore how child correlates may be similar across cultures, although cultures may differ in their emphasis on particular parenting practices (i.e., mean levels).

\section{Maternal versus Paternal Authoritarian Control and Child Aggression: Studies in China}

As noted earlier, a number of important studies have shown that aversive Chinese parenting is associated with aggressive child behavior. This finding is consistent with the long-held assumption that unqualified power assertion (e.g. commands, threats, deprivations, and physical force) likely evokes feelings of hostility and opposition toward parents and therefore interferes with children's proper internalization of control (Hoffman, 1960). Similarly, Confucian tradition requires that the elder generations "responsibly and justly govern, teach, and discipline" (Chao, 1994, p. 1113). It seems unlikely that aversive parenting would be perceived by children to represent responsible and just government by their elders. Furthermore, social learning theory also presumes that children learn and adopt aggressive strategies through watching and interacting with aggressive models (Bandura, 1973; Coie \& Dodge, 1998; Crick et al., 1999). In this context, parents serve as models from which children expect to learn more or less effective strategies for social interaction. In particular, children's aggressive styles may parallel the particular coercive or controlling disciplinary style enacted by parents. This assumption is the foundation for this study, which probes for associations between physical and psychological forms of coercive and controlling parenting and aggression subtypes (physical and relational). Furthermore, we particularly emphasize the interplay of maternal and paternal negative parenting effects on child outcomes.

Consistent with this emphasis, a number of studies of negative parental control that have in- cluded both Chinese mothers and fathers are relevant to this discussion. In particular, the relation between negative parenting and childhood aggression in these studies is the focus of this brief review. First, Chen and colleagues have conducted a number of relevant studies with samples from Beijing, China. For example, Chen et al. (1997) conducted a series of regression analyses to examine relative contributions of maternal and paternal authoritarian parenting to the prediction of academic and social outcomes in 8 -year-old children. The results showed that, for most variables, Chinese fathers' authoritarian parenting predicted child outcomes above and beyond maternal parenting styles. Of particular interest to the current study is that paternal authoritarian parenting predicted children's aggressive-disruptive behavior. In a later study, Chen et al. (2001) found that observed aggressive behavior (an aggregate of verbal, physical, and indirect forms) of 4-year-old children in China was associated with Chinese parenting. Paternal power assertion, in particular, was positively associated with aggression in girls. Maternal power assertion was also a significant contributor if the father was high on power assertion as well. Furthermore, in a longitudinal study, Chen et al. (2002) also found associations between maternal and paternal reports of powerassertive childrearing at age 2 and child physical and verbal aggression exhibited 2 years later. In particular, maternal power assertion marginally predicted later aggression for boys and girls. In contrast, paternal power assertion was highly predictive of subsequent aggression in boys (but not girls).

Chang and colleagues have also contributed to our understanding of negative child outcomes related to authoritarian parenting in China. In particular, they found that harsh parenting on behalf of Chinese mothers and fathers was both directly and indirectly (through emotional regulation) tied to child physical aggression/bullying in a kindergarten sample (Chang et al., 2003). Furthermore, these effects varied somewhat by gender of parent and child. Specifically, harsh parenting on behalf of mothers linked to child emotional regulation more strongly than that of fathers. In contrast, fathers' harsh parenting had a greater impact on child aggression, and sons appeared to be affected more than daughters by paternal rejection.

\section{Considering Psychological Control and Relational Aggression}

As noted above, research has also begun to focus on psychological control in China, although this research focus is new in Western culture as well. For 
our purposes, psychological control is most interesting to consider given its parallel form to relationally aggressive behaviors in children. Crick and Grotpeter (1995) define relational aggression as acts involving manipulation or damage to social relationships (e.g., exclusion, backbiting, or threats of social harm). Previous research shows that children readily engage in relational aggression as early as preschool (e.g., Nelson, Robinson, \& Hart, 2005; Ostrov, Woods, Jansen, Casas, \& Crick, 2004). To date, the majority of childhood aggression research in China has focused on physically aggressive or disruptive behaviors in Chinese children. Accordingly, a focus on relational aggression in China is a welcome addition to the literature.

Consistent with a social learning theory perspective, one might reasonably surmise that unique parental control strategies might be differentially related to child aggression subtypes. In particular, physically coercive parenting might provoke physically aggressive behavior in children, whereas psychological control strategies might relate to the development of relational aggression in children. For example, one of the components of psychological control is love withdrawal, in which parents may withhold love and attention when they are displeased with the child's actions or they desire to manipulate the child into a particular course of action. This strategy is consistent with relational aggression, in which the vehicle of harm is damage or the threat thereof to relationships. Exclusionary behaviors enacted in the peer group seem parallel to what a child may experience with a psychologically controlling parent.

However, the specificity of relationships posited between parental control styles and childhood aggression subtypes has received only partial support in studies to date, and findings have varied across cultures and parent-child dyads (e.g., Nelson \& Crick, 2002; Yang et al., 2004). Generally speaking, parental coercion and psychological control were associated with both forms of aggression in these studies. Nonetheless, despite a general lack of specificity, the correlation between coercive and psychologically controlling parenting and aggression subtypes appears to be robust across a number of cultures (see also Hart, Nelson, Robinson, Olsen, \& McNeilly-Choque, 1998; Hart, Nelson et al., 2000). Building upon this previous work, the present study further examines the effects of both physically coercive and psychologically controlling parenting on these childhood aggression subtypes in a sample of Beijing preschoolers. Furthermore, the novel statistical method utilized in this study may yield more clarity in regard to specificity of relationships between forms of parental control and aggression subtypes. In addition, this study also differs slightly from previous studies of both forms of control and aggression subtypes in that coercion is limited to physical elements in this study (whereas coercion in previous studies was a combination of physical and verbal elements). This adjustment (excluding verbal coercion) was made in order to eliminate possible confounds with verbal elements of psychological control.

\section{Similarity and Differences in Parenting: Insights From the Coparenting Literature}

Another important focus of this study is consideration of what impact combined or differential parental effects may have on child outcomes. Beyond the need to simply include fathers in parenting studies, a number of previous studies in the coparenting literature have intended to focus on the interdependent or combined influence of mothers and fathers (Cabrera, Tamis-LeMonda, Bradley, Hofferth, \& Lamb, 2000; Deal, Halverson, \& Wampler, 1989; Lindsey \& Mize, 2001; Russell \& Russell, 1994; Winsler, Madigan, \& Aquilino, 2005). These studies (all conducted with Western samples) have yielded results suggesting that similarity in parenting is common and may be associated with unique child outcomes.

For example, Russell and Russell (1994) found considerable similarity between mothers and fathers across a range of parenting values and behaviors. Hart, DeWolf, Wozniak, and Burts (1992) also classified mothers and fathers as either inductive or power assertive and found similarity in discipline style in $65 \%$ of the mother-father dyads. In a more recent study, Winsler et al. (2005) found that parents reported modest similarity for permissive and authoritarian parenting but not for authoritative parenting. Moreover, Lindsey and Mize (2001) found that mothers' and fathers' similarity in play initiations (ranging from invitations to imperative commands) was associated with children's social competence.

In order to better understand parenting similarity and differences, researchers must clarify which components of parenting tend to be the focus of more or less agreement and why. It is also relevant to understand how patterns of parenting agreement or difference might influence child development in different ways, and across different cultures. Accordingly, this study expands the focus of research on parenting consistency to multiple forms of aversive parenting within a non-Western culture. To our knowledge, no study has explicitly considered parenting similarity and difference in the Chinese culture. 


\section{Assessing Combined and Differential Contributions of Mothers and Fathers}

In alignment with the above emphasis on parenting similarity and difference, this study utilizes a unique statistical model. In particular, a twogroup (boys and girls) sum and difference structural equation model was estimated. In this model (see Figures 1 and 2), maternal and paternal parenting variables are re-expressed as second-order combined and differential components (of physical coercion as well as psychological control) in order to represent (a) the summed or combined effects of maternal and paternal parenting and (b) the extent to which parents may differentially exhibit a behavioral profile. The specifics of this approach are provided in detail below. This approach helps to provide answers to questions regarding the interplay of maternal and paternal influence. In particular, this approach allows for evaluation of whether the combined or differential impact of mothers' and fathers' negative parenting is uniquely predictive of aggression subtypes in boys and girls.

\section{Method}

\section{Participants}

Behavior nomination data were obtained in this study for 215 children (100 boys; 115 girls) from nine classrooms in two preschools in Beijing, China. There was an average of 23.9 children per classroom. Minimum participation rates of $95 \%$ in the peer behavioral nomination procedure were present for all classrooms. Given the nature of a nomination assessment, aggression scores were obtained for all 215 children. Ages of the children ranged from 46 to 76 months $(M=61$ months). Schools in China act in loco parentis, and thus we were not allowed to obtain written parental permission for each child's participation (cf. Chen et al., 1992; Hart, Yang et al., 2000). However, study procedures were explained to parents in group meetings that school administrators helped arrange. At these group meetings, teachers and parents were assured of confidentiality of all responses in the study. Parents were also told that they could withdraw themselves or their child from study participation at any time. The parenting questionnaires were given to parents in one of three separate packets of measures (as part of a larger study of familial influences on children's social development) with instructions on how to complete them. Parents were allowed to take the questionnaire packets home one at a time and returned consecutive packets on a weekly rotation. Each packet required approximately 30-45 min to complete. During this 3week period, child behavior nomination assessments were conducted in the preschool classrooms.

Of the parents of the 215 potential families, 180 mothers (84\%) and 167 fathers (78\%) returned the packets which included the questionnaires of interest for this study. Parent participants ranged in age from 26 to 52 years $(M=34.1$ years). Their formal education ranged from 5 to 22 years in length $(M=13.9$ years). This sample may generally be considered highly educated as parents with a bachelor's or more advanced degree accounted for $32.8 \%$ of the sample. Given that we had behavior nomination data for 215 children, missing parental data was accounted for in the analyses below using full information maximum likelihood estimation.

\section{Measures}

In prelude to a description of each of the measures utilized in this study, it is important to note that all measures were carefully forward- and back-translated and pilot-tested with Chinese parents and children in order to ensure conceptual equivalence of the measures (meaning that they should be similarly understood by individuals in both Chinese and Western samples).

Assessment of child aggression subtypes. This study used a peer nomination procedure to obtain children's relational and physical aggression scores. The behavioral nomination items are listed in Table 2 . These items, originally adapted from the work of Crick, Casas and Mosher (1997), have demonstrated reliability in previous research (McNeilly-Choque, Hart, Robinson, Nelson, \& Olsen, 1996). Children were individually interviewed, using picture-board nomination procedures developed in other studies with young children (e.g., Crick et al., 1997; McNeillyChoque et al., 1996). As part of the larger study of children's social development, a number of other social behaviors (e.g., social withdrawal) were also assessed in these interviews. For each item, children nominated up to six classmates whom they perceived to engage in the behavior described. The number of nominations received for each item was standardized within each classroom and further analyses were based on these standardized scores.

Assessment of parenting dimensions. Because of concerns about self-report bias in parenting assessments, an alternative is a spouse-report paradigm (Nix et al., 1999; Porter et al., 2005; Russell, Hart, Robinson, \& Olsen, 2003; Yang et al., 2004). Accord- 
ingly, the procedure in this study required parents to independently rate their spouse's parenting styles and practices with items adapted from measures of authoritarian and authoritative dimensions of parenting (Robinson, Mandleco, Olsen, \& Hart, 2001) as well as psychological control (see Barber, 1996; Olsen et al., 2002; Yang et al., 2004). Representative items are listed in Table 3, and these items have been reliably used in previous studies (e.g., Nelson \& Crick, 2002; Yang et al., 2004). Parents rated the frequency of their spouse's engagement in specific parenting behaviors utilizing a 5-point Likert-type scale $(1=$ never $; 5=$ always $)$.

\section{Analyses}

Structural equation modeling was used to model the relations among the latent variables of interest in this study. All models were fit using the Mplus statistical program, using categorical analysis of the data (Muthén \& Muthén, 2001). In particular, in regard to the measurement models, two sets of multigroup confirmatory factor analyses were conducted (for child aggression and negative parenting), including an assessment of factorial invariance across groups in the measurement models (Widaman \& Reise, 1997). Invariance constraints are used in order to ensure that the same latent variables are identified across child gender (boys and girls when measuring aggression) or both parent and child gender (fathers and mothers of boys and girls when measuring aversive parenting). Finally, in regard to reliability of measurement, it is important to note that coefficient $\alpha$ is not typically reported in confirmatory factor analysis procedures as latent variables are not multiple-item scales and $\alpha$ values therefore cannot be calculated. Rather, standardized factor loadings of .40 and above are considered as evidence of reliability in structural equation modeling for samples of 150 or more (Stevens, 1996).

\section{Specifics of the Latent Sum and Difference Structural Equation Modeling}

As noted above, this study uses a latent sum and difference structural equation model in which levels of negative parenting, for mothers and fathers, can be better examined. Recognizing that under bivariate normality it is possible to reexpress the statistical information contained in two variables (e.g., the parenting of a mother and father) in terms of their corresponding sum and difference, we have used a basic two-component approach. In this model, the latent maternal and paternal parenting variables are reexpressed in terms of (a) the cumulative level of negative parenting by both parents (i.e., the sum or combined component) and (b) the extent to which one parent might enact a negative parenting behavior to a greater degree than the other parent (i.e., the potential difference or differential component). Accordingly, these combined and differential components are represented as second-order dyadic latent constructs that embody theoretically central aspects of the (first-order) maternal and paternal latent variables. These constructs are directly analogous to the latent intercept and slope in a traditional latent growth "curve-of-factors" model (Duncan, Duncan, Strycker, Li, \& Alpert, 1999).

The combined component of our approach acknowledges that the cumulative effect of parents who engage together in high levels of negative parenting will vary considerably from other parents who jointly enact relatively low levels of the same parenting behaviors. In contrast, the differential component recognizes that, in many parental dyads, mother and father may enact parenting behaviors in a more or less divergent or discrepant fashion. In particular, mothers and fathers may not always be enacting a common script as they interact with their child. Hence, the focus of the differential component is on the degree of parenting similarity.

Because the combined and differential constructs represent direct reexpressions of the original mother and father latent variables, the variance they account for in child outcomes is necessarily identical to that obtained using the original mother and father constructs as predictors. Accordingly, owing to this statistical equivalence, the suitability of our model is based primarily on theoretical and interpretational benefits rather than on any presumed mathematical advantage over traditional regression approaches (i.e., using separate maternal and paternal constructs).

To be specific, the primary benefit of our approach is that it allows us to view "parenting" as deriving from the parental dyad and the interplay of the dyad members, rather than being enacted separately as "mothering" and "fathering" by individuals independently trying to nurture or deal with the same child. In other words, rather than individual parenting effects, the second-order latent constructs represent dyadic properties which we believe more accurately represent the joint nature of parenting. Thus, in predicting child outcomes, whereas a standard regression model would focus on the combined effects of individual parents, our sum and difference model focuses on effects of combined parenting variables, which are assembled to represent the dyadic context and properties of these measures. With our 
approach, then, combining mother and father parenting contributions is primarily a matter of variable construction rather than model estimation and statistical analysis.

To define the model, fixed paths (see numbers in parentheses in Figures 1 and 2) are used to model the information from the maternal and paternal parenting variables in terms of these second-order latent variables. In particular, the sum (combined) variable has fixed paths of 1.0 to each of the two (mother and father) parenting variables, representing the combined elements of the maternal and paternal variables. In contrast, there are fixed paths from the difference (differential) variable to the mother and father parenting variables of 1.0 and -1.0 , respectively, indicating the degree of discrepancy or divergence in the levels of the first-order (mother and father) latent variables. Accordingly, the differential component assesses whether there is a systematic gender-based difference between parents (i.e., mother $>$ father) that is uniquely predictive of aggression outcomes. Furthermore, given that the differential paths are fixed at 1.0 (to the maternal variable) and -1.0 (to the paternal variable), a positive coefficient demonstrates an influence in favor of mothers whereas a negative coefficient demonstrates an influence in favor of fathers.

An ordinary least squares (OLS) regression model, based on summing and subtracting scales created from the observed parenting scores, produces similar findings. The essential difference is that the magnitudes of the OLS regression coefficients are attenuated given that measurement error is not taken into account. Beyond measurement error, other issues also hamper the regression approach (e.g., treating the ordinal data as interval, equal [nonoptimal] weighting of the items when forming the parenting scales, inability to handle missing data). For these reasons, the structural equation modeling approach is preferable to a regression model in that it yields more powerful tests and more accurate estimates of the effects of interest. The results of the regression analyses are available to interested readers from the corresponding author.

\section{Results}

Descriptive Statistics and Intercorrelations of the Observed Variables

An intercorrelation matrix of all observed variables is provided in Table 1, with means and standard deviations for each observed variable. The correlation matrix and descriptive statistics are provided separately by gender of child, given that the analysis structure reflects this emphasis to focus on associations separately for boys and girls. Variable numbers correspond with the numbering provided in Tables 2 and 3 (e.g., PPC $1=$ Paternal Psychological Control Item \#1). Although our analysis with MPlus uses special procedures for categorical (ordinal) data, the normal-theory Pearson correlations are given here along with the means and standard deviations to provide a familiar descriptive picture of the average levels, distributions, and relationships among the variables.

\section{Measurement Model of Childhood Aggression Subtypes}

In regard to the measurement of childhood aggression, the baseline measurement model (constrained model) of the aggression constructs fit the data satisfactorily: $\chi^{2}=39.74, d f=29, p=.02, C F I=.98, T L I=$ .97 , and $R M S E A=.06$. Furthermore, the unconstrained model showed no significant improvement in the goodness of fit: $\chi_{\text {diff }}^{2}=5.54, d f_{\text {diff }}=5, p=.36$. Thus, invariant measurement of the aggression constructs was obtained for boys and girls. The standardized factor loadings of the baseline model are shown in Table 2 for both boys and girls.

Because of the high latent correlation of the two aggression constructs $(\varphi \approx .88$ in boys and .80 in girls), an additional model using similar indicators to reflect a single aggression construct was compared with the baseline (two-construct) model (this comparison was conducted for boys and girls together). The chi-square difference test showed that the original two-construct model fit the data better than the one-construct model: $\chi_{\text {diff }}^{2}=24.39, d f_{\text {diff }}=3, p<.01$. Thus, the two constructs were statistically distinguished, although they are highly correlated. Furthermore, the equivalent Pearson's $r s$ for the aggression scale scores ( $r \mathrm{~s}=.74$ and .50 for boys and girls, respectively) were similar to values reported in prior research regarding physical and relational aggression (Crick et al., 1999; McNeilly-Choque et al., 1996; Nelson et al., 2005; Park et al., 2005). In particular, in a meta-analysis of early studies in relational aggression, Crick et al. (1999) reported that physical and relational aggression were highly correlated for both peer and teacher ratings ( $r$ s of .62 and .63, respectively) and the correlations were consistently higher for boys $(r s=.75$ and .73 for boys, .60 and .61 for girls, for peer and teacher ratings, respectively).

Despite the high correlation, numerous examples of criterion validity have distinguished relational and physical aggression across a significant number 


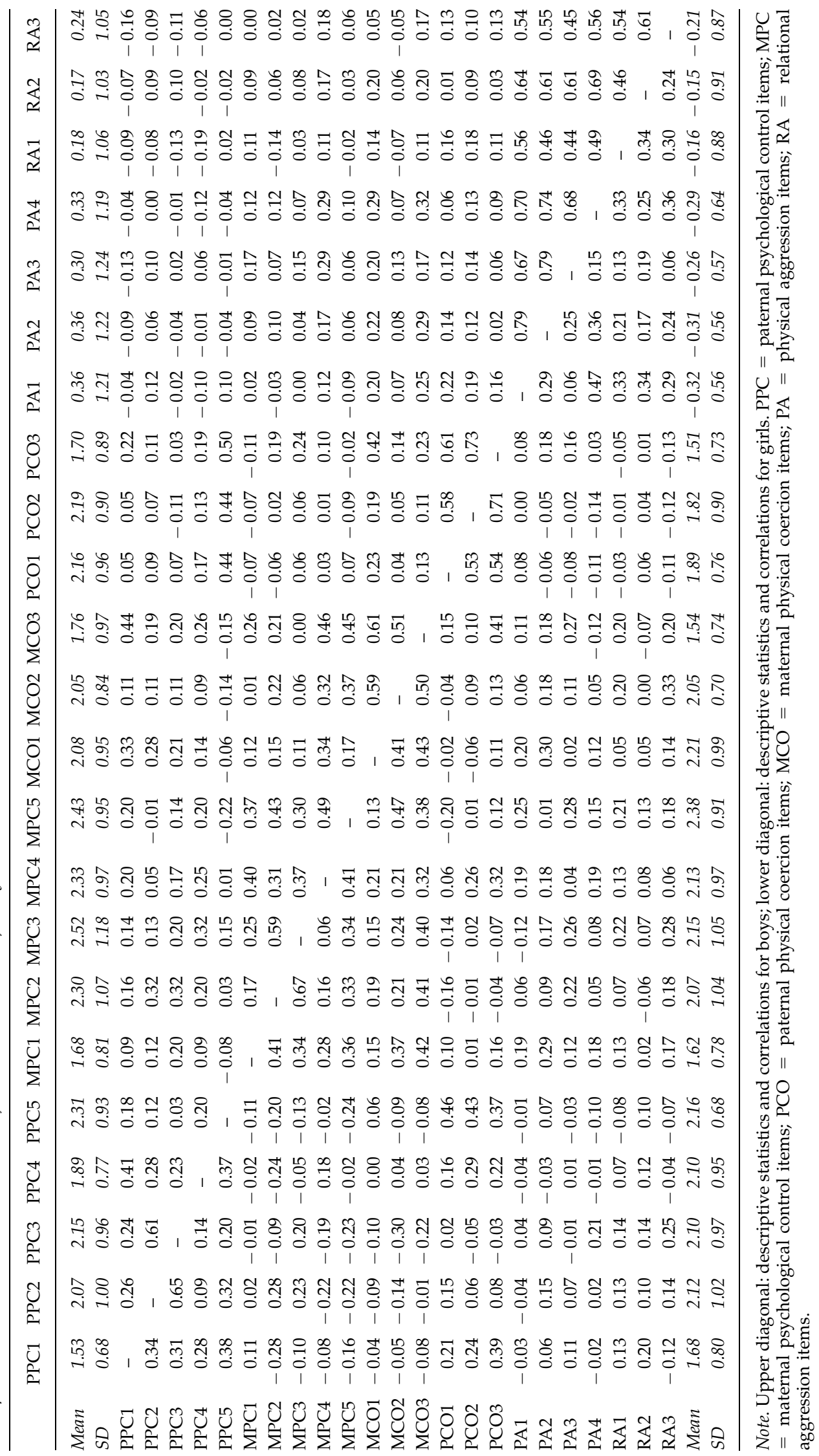


Table 2

Standardized Factor Loadings of the Aggression Constructs

\begin{tabular}{|c|c|c|}
\hline \multirow[b]{2}{*}{ Constructs and Contents } & \multicolumn{2}{|c|}{ Loadings } \\
\hline & Boys & Girls \\
\hline \multicolumn{3}{|l|}{ Physical aggression } \\
\hline $\begin{array}{l}\text { 1. Who likes to mess up or knock down } \\
\text { other children's things? }\end{array}$ & .86 & .66 \\
\hline $\begin{array}{l}\text { 2. Who grabs toys or things from other } \\
\text { children? }\end{array}$ & .91 & .57 \\
\hline $\begin{array}{l}\text { 3. Who pushes other kids out of the way to } \\
\text { get something they want? }\end{array}$ & .83 & .45 \\
\hline $\begin{array}{l}\text { 4. Who starts (physical) fights with other } \\
\text { children? }\end{array}$ & .83 & .62 \\
\hline \multicolumn{3}{|l|}{ Relational aggression } \\
\hline $\begin{array}{l}\text { 1. Who tells some other kids not to be } \\
\text { friends with someone? }\end{array}$ & .63 & .56 \\
\hline $\begin{array}{l}\text { 2. Who won't let some kids sit beside them } \\
\text { because they don't like them? }\end{array}$ & .82 & .51 \\
\hline $\begin{array}{l}\text { 3. Who tells other kids they cannot play } \\
\text { unless they do what everyone wants them } \\
\text { to do? }\end{array}$ & .74 & .55 \\
\hline
\end{tabular}

Note. All items were shown to be invariant across child gender.

of studies (Crick et al., 1999). Furthermore, although physical and relational aggression tend to be highly correlated, they are not redundant. This is especially true for girls in our study, for whom the scores on one aggression form account for only $25 \%$ of the variance for the other form. Although the overlap is much higher for boys, about $45 \%$ of the variance still remains to be explained. Furthermore, previous research shows that youths identified as extreme for aggression status are more likely to primarily display one form of aggression rather than to be comorbid for both (Rose, Swenson, \& Waller, 2004). Thus, it is important to consider possibly unique contributors to the development of these aggression subtypes. For the purposes of this study, what is most telling is whether unique findings between aggression subtypes and parenting behaviors exist and thereby provide important information about specific parent-child interaction, despite the overlap between aggression subtypes. This will be seen in the model testing described below.

\section{Measurement Model of Parental Physical Coercion and Psychological Control}

The factor loadings of maternal coercion and psychological control were also constrained to be equal to the corresponding factor loadings of the paternal parenting constructs across and within the two groups (boys and girls). The baseline model fit the data satisfactorily: $\chi^{2}=88.17, d f=63$, $p=.02, C F I=.94, T L I=.95$, and $R M S E A=.07$. The unconstrained model showed no significant improvement in model fit, $\chi_{\text {diff }}^{2}=22.07, d f_{\text {diff }}=13$, $p=.054$, implying that the factor loadings were invariant across gender of both parents and children. The standardized factor loadings of the baseline model are listed in Table 3. In addition, the correlations between the various parenting constructs (conducted separately by child gender) are listed in Table 4.

Finally, owing to the relatively high latent correlations between coercion and psychological control (especially for mothers), another model that combined the two constructs (a combined parenting construct for both fathers and mothers) was estimated and compared with the baseline two-factor

Table 3

Standardized Factor Loadings of Parental Control Constructs for Various Parent-Child Dyads

\begin{tabular}{|c|c|c|c|c|}
\hline \multirow[b]{2}{*}{ Constructs and Contents } & \multicolumn{2}{|c|}{ Mothers } & \multicolumn{2}{|c|}{ Fathers } \\
\hline & Boys & Girls & Boys & Girls \\
\hline \multicolumn{5}{|l|}{ Physical coercion } \\
\hline 1. Spanks when our child is disobedient & .76 & .44 & .73 & .65 \\
\hline 2. Slaps our child when the child misbehaves & .72 & .74 & .69 & .65 \\
\hline \multicolumn{5}{|l|}{ Psychological control } \\
\hline 1. Becomes less friendly with our child if our child does not see things his or her way & .55 & .68 & .51 & .58 \\
\hline 2. Makes our child feel guilty when our child does not meet our expectations & .53 & .48 & .40 & .42 \\
\hline 3. Tells our child that we get embarrassed when she or he does not meet our expectations & .50 & .50 & .42 & .44 \\
\hline 4. Tells our child he or she is not as good as other children & .72 & .54 & .57 & .47 \\
\hline 5. Loses temper easily with our child & .61 & .51 & .45 & .65 \\
\hline
\end{tabular}

Note. All items were shown to be invariant across both parent and child gender. 
Table 4

Estimated Latent Variable ( $\phi$ ) Correlations of the Parenting Constructs

\begin{tabular}{lcccc}
\hline & $\begin{array}{c}\text { Maternal } \\
\text { coercion }\end{array}$ & $\begin{array}{c}\text { Maternal psychological } \\
\text { control }\end{array}$ & $\begin{array}{c}\text { Paternal } \\
\text { coercion }\end{array}$ & $\begin{array}{c}\text { Paternal psychological } \\
\text { control }\end{array}$ \\
\hline Maternal coercion & - & $.70^{* * *}$ & .16 & -.24 \\
Maternal psychological control & $.52^{* *}$ & - & .12 & $-.33^{*}$ \\
Paternal coercion & .28 & .09 & - & $.58^{* *}$ \\
Paternal psychological control & $.52^{* *}$ & $.54^{* *}$ & $.38^{*}$ & - \\
\hline
\end{tabular}

Note. ${ }^{*} p<.05 ;{ }^{* *} p<.01 ;{ }^{* * *} p<.001$.

Upper diagonal: correlations among parenting variables for girls; lower diagonal: boys.

model. The chi-square difference showed that the baseline two-factor model fit the data better than the combined model: $\chi_{\text {diff }}^{2}=16.63, d f_{\text {diff }}=5, p<.01$. Thus, these two parenting constructs were statistically distinguished, although they are significantly correlated.

\section{Combined and Differential Prediction of Childhood Aggression}

In regard to testing the latent sum and difference model, the model fit the data satisfactorily: $\chi^{2}=110.35, d f=81, p=.02, C F I=.92, T L I=.93$, and $R M S E A=.06$. The parameter estimates are shown in Figures 1 (the model as estimated for girls) and 2 (the model as estimated for boys). Sig- nificant findings were obtained for both boys and girls. As shown in Figure 1, there are relatively strong effects of combined psychological control on daughters' aggression. In particular, the degree to which mothers and fathers cumulatively engage in psychological control was significantly related to both physical aggression $(\beta=.55, z=3.05$, $p<.01)$ and relational aggression $(\beta=.64, z=2.68$, $p<.01)$ in girls. In contrast, combined physical coercion was unrelated to either form of aggression in girls. In addition, a couple of findings for differential effects were obtained for relational aggression in girls. First, there was a significant effect of differential psychological control on relational aggression $(\beta=-.50, z=-2.15, p<.05)$. The negative valence of the $\beta$ coefficient demon-

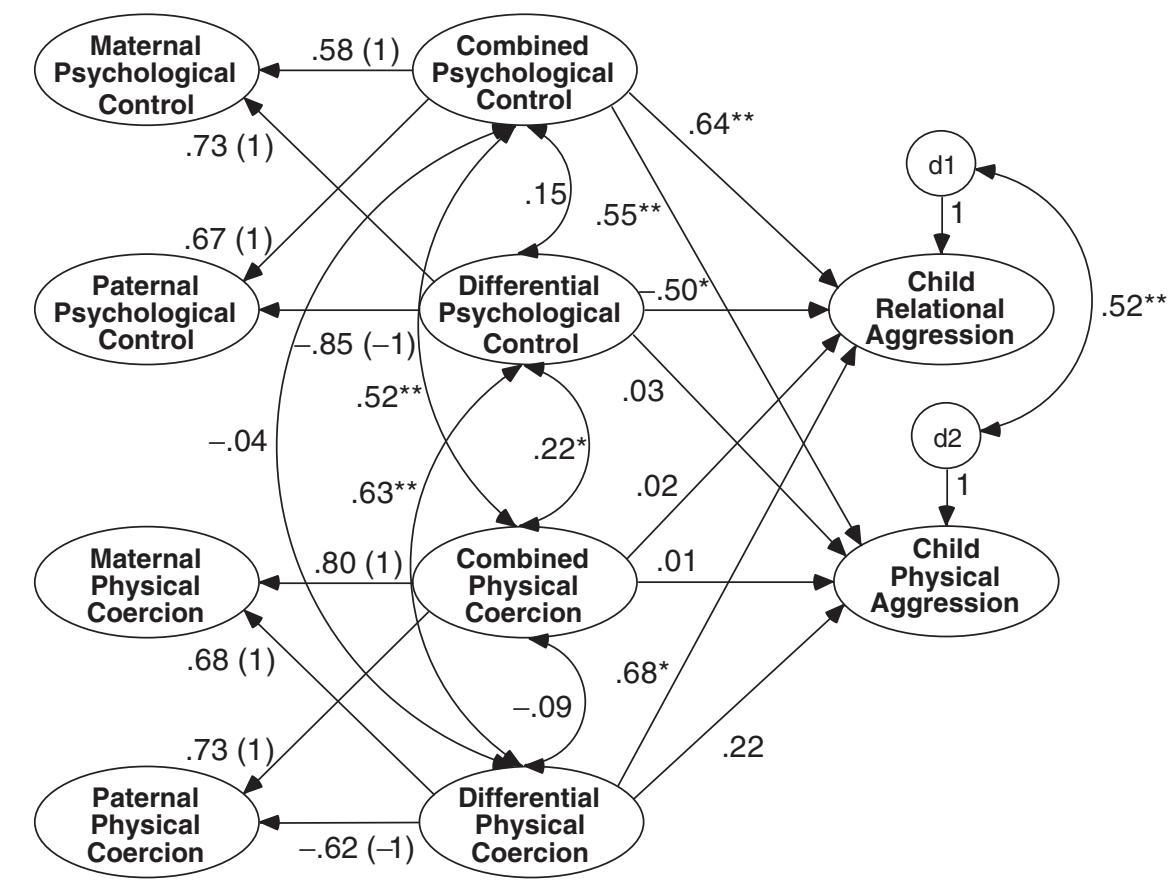

Figure 1. Latent sum and difference model for girls. Note. ${ }^{*} p<.05 ;{ }^{* *} p<.01$. Numbers in parentheses represent the measurement equations necessary to accomplish the statistical modeling. 


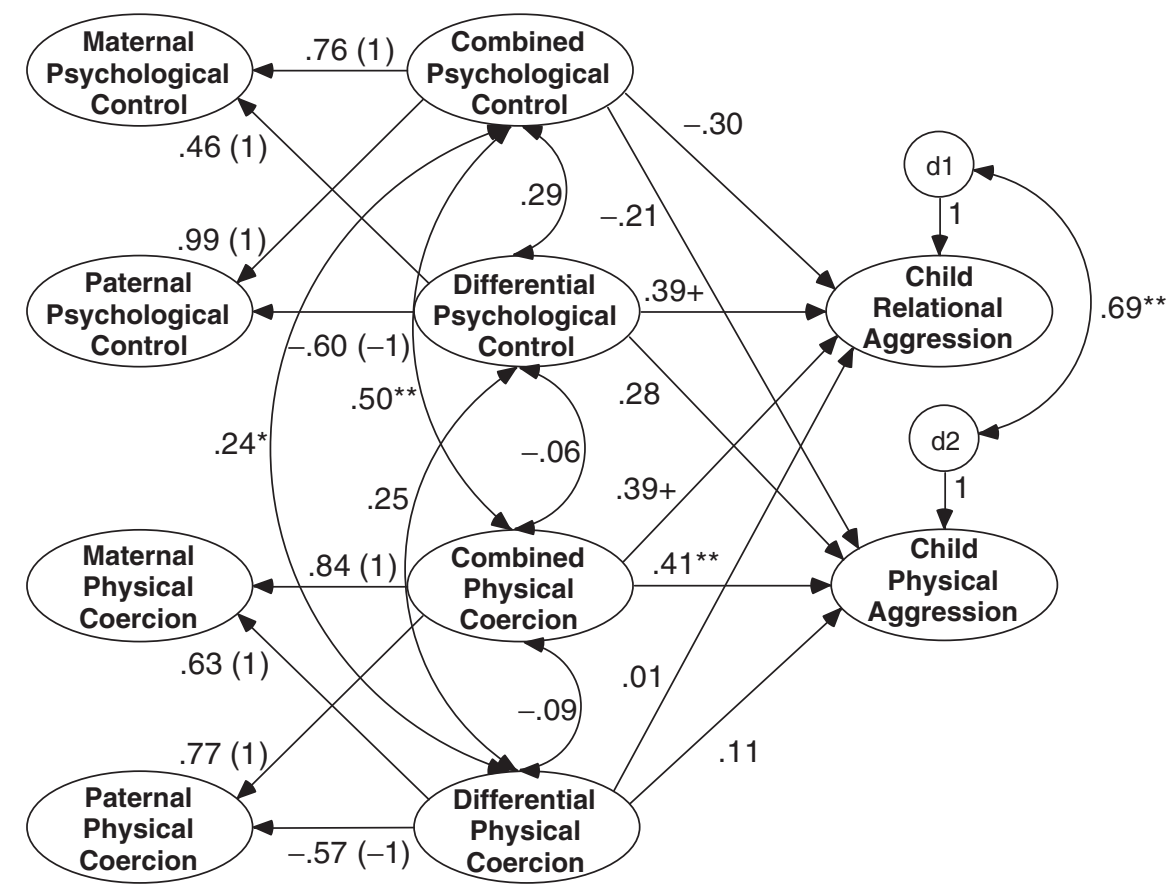

Figure 2. Latent sum and difference model for boys. Note. ${ }^{+} p<.07{ }^{*} p<.05 ;{ }^{* *} p<.01$. Numbers in parentheses represent the measurement equations necessary to accomplish the statistical modeling.

strates that, to the extent that fathers, relative to mothers, consistently engage in higher levels of psychological control, the difference is predictive of relational aggression in girls. In addition, there was a significant effect of differential physical coercion on relational aggression $(\beta=.68$, $z=2.44, p<.05)$ in girls. In this case, the positive valence of the beta coefficient demonstrates that, to the extent that a mother, relative to her spouse, consistently engages in higher levels of physical coercion, the difference is predictive of greater levels of relational aggression in girls.

A more modest set of significant findings was obtained for boys. As shown in Figure 2, combined psychological control is unrelated to either form of aggression whereas combined physical coercion significantly predicts physical aggression $(\beta=.41$, $z=2.65, p<.01)$ and marginally predicts relational aggression $(\beta=.39, z=1.91, p=.06)$ for boys. Finally, differential psychological control was marginally predictive of relational aggression $(\beta=.39, z=1.82$, $p=.07)$ in boys. This finding suggests that, to the extent that mothers consistently engage in higher levels of psychological control than their husbands, the difference is marginally predictive of greater engagement by Chinese boys in relational aggression. Differential physical coercion, in contrast, was unrelated to boys' aggression (relational or physical).

\section{Discussion}

In support of past research, this study found physically coercive and psychologically controlling parenting to predict aggression in Chinese children. Furthermore, the latent sum and difference structural equation model allowed for a unique look at how maternal and paternal variables may be associated with childhood aggression, considering both combined and differential effects. In regard to combined effects, significant results showed that, to the extent that Chinese mothers and fathers cumulatively engage in more psychological control, but not physical coercion, daughters are more likely to be physically and relationally aggressive with peers. In contrast, when Chinese mothers and fathers jointly engage in more physical coercion, as opposed to psychological control, sons are more likely to be physically aggressive. As noted earlier, the combined and differential effects analyzed in this study are unique in that they allow us to view parenting as a property of the parental dyad, thereby acknowledging that cumulative and differential levels of childrearing may have significant implications for child outcomes.

A couple of significant differential effects were also obtained in predicting aggression for girls. First, to the extent that Chinese mothers, relative to fathers, engage in more physical coercion with daughters, 
girls are more relationally aggressive. Second, to the extent that Chinese fathers, relative to mothers, engage in more psychological control, girls are more relationally aggressive. It is unclear why significant differential effects were not obtained for boys (although one path approached significance). These results suggest that inconsistencies in parenting may contribute uniquely to the appearance of aggressive behavior in Chinese children, especially girls. Overall, the combined and differential effects also suggest that specificity of relationships between forms of aversive parenting and child aggression subtypes (e.g., physical coercion being predictive of physical but not relational aggression) are hard to come by.

Of interest is the finding that the effects of aversive parenting appeared to differ by gender of child. In particular, aggression in girls was predominantly linked to psychological control whereas physical coercion was associated with aggressive behavior in boys. These findings suggest that sensitivity to parental control may vary by gender. This notion of gendered sensitivity appears consistent with Western data regarding the impact of relational aggression in the peer group. Relational aggression is often cited as the most representative form of aggressive peer interaction among girls (Crick, Bigbee, \& Howes, 1996; Crick \& Grotpeter, 1995; Crick et al., 1999; French, Jansen, \& Pidada, 2002; Park et al., 2005). In addition, prior research also shows that the interpersonal nature of relationally aggressive episodes (social exclusion, gossip, disagreements with friends) is more upsetting for girls than for boys (Crick, Grotpeter, \& Bigbee, 2002; Leadbeater, Blatt, \& Quinlan, 1995; Leadbeater, Kuperminc, Blatt, \& Hertzog, 1999; Rudolph \& Hammen, 1999; Rudolph et al., 2000). Thus, it appears that the sensitivities of girls may be consistent across the parent-child and peer group contexts, in that girls appear to be more sensitive to behaviors that manipulate or threaten established relationships in either context.

In contrast, boys are consistently found to be more physically coercive with peers than their female counterparts (Coie \& Dodge, 1998; Crick et al., 1999) and most distressed by instrumental concerns and physical dominance issues (Leadbeater et al., 1995, 1999; Rudolph \& Hammen, 1999; Rudolph et al., 2000). Accordingly, physically coercive parenting appears to parallel the types of provocations that matter most to boys in the peer group. Therefore, if the same sensitivities apply in China for boys and girls (a matter for future research to document), psychological control or physically coercive control may hold more sway in influencing the behaviors of girls or boys, respectively. This gender-sensitivity perspective contrasts with previous hypotheses that the effects of aversive parenting on child aggression may be most pronounced in same-gender parentchild dyads (Deater-Deckard \& Dodge, 1997).

Although a number of previous studies of aversive parenting and child aggression have been conducted in China (Chang et al., 2003, 2004; Chen et al., 1997, 2001, 2002; Olsen et al., 2002; Yang et al., 2004), few studies have focused on psychological control, a type of discipline considered to be an "intrusion into the developing child's self-expression-whatever form of expression that might be" (Barber, 1996, p. 3315). There is need to study the impact of this parenting style on self-expression as it varies from young childhood through late adolescence. The results of this study show that psychological control is connected to child behavioral difficulties as early as preschool, when self-expression is yet in its formative stages.

The results of this study also provide greater understanding of the range of controlling behaviors that Chinese parents may engage in, thereby contributing to the current debate over the meaning of authoritarian control. This study appears to confirm the common-process viewpoint as it relates to harsher forms of parenting. Particularly negative parenting (physical coercion and psychological control), shown to be associated with children's aggression in Western studies, also predicts negative child outcomes in China. Thus, authoritarian parenting, contrary to Chao's (1994) initial contentions, is not irrelevant in describing the nature and influence of Chinese parenting. Nonetheless, there may also be important cultural differences in less extreme forms of authoritarian parenting (e.g., Chao's notion of training). There is also value in looking beyond parenting constructs originally derived in Western cultures to identify potentially indigenous parenting constructs that coincide with unique child outcomes (Chao, 1994; Wu et al., 2002). Further studies are needed to assess whether "training" is associated with more than academic outcomes for Chinese children. Furthermore, Chao's work has focused on adolescents, and studies with other age groups are needed to assess whether training is an important parenting phenomenon across development.

The findings of this study are in alignment with Rohner's parental acceptance-rejection theory (PARTheory; Khaleque \& Rohner, 2002), which posits that children's psychological adjustment is directly related to the degree to which they feel accepted by their parents. In particular, Rohner hypothesizes that this association holds for children anywhere in the world, irrespective of their unique culture, ethnicity, 
race, gender, or socioeconomic status. Hostility/aggression is considered to be one of the fundamental reactions to denial of parental acceptance, and the results of this study further enhance the evidence supporting this hypothesis, inclusive of both physical and relational forms of aggression.

Furthermore, on the basis of PARTheory, a child's perceptions of parental acceptance or rejection may be the defining feature of possible cultural differences in indigenous meanings of parental behavior. This is consistent with the foundation of Chao's argument that milder forms of authoritarian parenting (nondemocratic control) in China - that she refers to as training - may be perceived by Chinese children as a sign of parental involvement and concern. In contrast, physically coercive and psychologically controlling parenting seem unlikely to be perceived by children in any culture to be a sign of parental acceptance. In line with this argument, Lau and Cheung (1987) have referred to order-maintaining and dominating control as respectively functional and dysfunctional forms of control in Asian parenting.

Some have argued, however, that aversive parenting, such as physical discipline, may vary in its effects by culture, in that (nonabusive) spanking, in the context of an otherwise warm relationship, may not contribute to child behavior problems (an idea consistent with the notion of parenting style; Baumrind, 1996). For example, there is currently controversy regarding the notion that corporal punishment among African Americans may not be associated with child aggression as it is in European Americans (e.g., Deater-Deckard \& Dodge, 1997; Polaha, Larzelere, Shapiro, \& Pettit, 2004). However, the findings appear equivocal as some studies find a negative relation, some no relation, and others a positive relation between physical discipline and child aggression among African Americans (Polaha et al., 2004). Furthermore, there is evidence that corporal punishment is associated with perceptions of parental rejection and negative psychological adjustment (including aggression) in cultures where the majority of both parents and children endorse its regular use and perceive it as good parenting (Lansford et al., 2005; Rohner, Kean, \& Cournoyer, 1991). Moreover, the idea that warmth in the parent-child relationship may moderate the relation between aversive discipline and child aggression has not been tested in many studies to date. One exception is that of McLoyd and Smith (2002), who analyzed the longitudinal connections between maternal spanking and problem behavior over a 6-year period (using the National Longitudinal Survey of Youth).
Findings were compared across European American, African American, and Hispanic children. Results showed that maternal emotional support moderated the connection between spanking and behavioral problems. In particular, spanking predicted increases in problem behavior over time in the context of low maternal emotional support. In contrast, no connection between spanking and problem behavior was observed in the context of high maternal emotional support. Significantly, this pattern of results held for all three ethnic groups, not just African Americans.

This study is also instrumental in advancing research related to the development of relational aggression in young children. In contrast with physical aggression, research regarding relational aggression or its correlates is relatively sparse. This is especially true in regard to familial contributions to relationally aggressive behavior (Park et al., 2005). This study is one of few studies that has empirically distinguished relational aggression from physical aggression in Chinese culture (see also Yang et al., 2004). Although relational aggression may be practiced in (yet unrecognized) culturally nuanced ways in China, successful measurement of the construct, based on current Western conceptualization, suggests that relational aggression may be generally applicable across cultures (Crick et al., 1999; French et al., 2002; Yang et al., 2004). The present study also extends past research in showing that relational aggression is significantly associated with negative parenting styles as early as preschool (e.g. Hart et al., 1998; Hart, Nelson et al., 2000; Yang et al., 2004).

Furthermore, the findings of this study reinforce the importance of considering the influence of both mothers and fathers. The majority of previous research examining parenting styles and practices has focused on maternal effects. This study further clarifies that Chinese fathers are important in ensuring the success of their children, whether it be social or academic (Chen et al., 2000: Ho, 1987; Stevenson, Chen, \& Lee, 1992). In fact, the results of studies conducted by Chen et al. and Chang et al., overviewed in the introduction, indicate that father influences may loom larger than mother effects in predicting childhood aggression in the Chinese culture. This assertion appears consistent with the Chinese proverb, "strict father, kind mother" (Lau et al., 1990). However, when statistically assessing the interplay of maternal and paternal influence, results of this study suggest that the cumulative and differential influence of mothers and fathers may each predict childhood aggression. Even though traditional and contemporary Chinese families emphasize the father as the authority figure (Chen et al., 
2001), the way that mothers interact with their children may carry equivalent weight in the socialization of aggression, especially when parents jointly engage in high levels of aversive parenting.

The statistical model estimated here reflects a direction of effect from parent to child. Yet difficult (aggressive) child dispositions may also elicit negative parenting, and the two may interact in systemic ways (Bell \& Chapman, 1986; Lytton, 1990). Accordingly, future research should test parent-child nonrecursive models having reciprocal effects. Generally speaking, Chinese parents use aversive parenting with greater frequency once children reach what Ho (1986) describes as the age of understanding, or dongshi, at around 6 years of age (see also Stevenson et al., 1992; Wu, 1996). Accordingly, although Chinese parents engage in sufficient behavior reflective of caring and concern, coercive and controlling patterns of interaction become more prevalent as children appear capable of understanding. Ho (1986) also emphasizes that certain child characteristics are more evocative of aversive parenting among Chinese parents. In particular, Chinese parents are preoccupied with emotional impulse control owing to cultural expectations that heavily emphasize modest and reserved behavior (cf. Porter et al., 2005). Accordingly, a Chinese child who exhibits physically or relationally aggressive behavior with peers (a manifestation of poor impulse control) may be especially prone to evoke negative parenting behavior (assuming parents are aware of such behavior). Alternatively, Larzelere, Kuhn, and Johnson (2004) have recently suggested that associations between physical discipline and child outcomes may be due to selection effects, as the frequency of any parental intervention (positive or negative discipline) may reflect the frequency of the child's misbehavior (to which the parent is responding). Future studies with more sophisticated research designs and analytic approaches (e.g., longitudinal studies, controlling for initial aggression) are needed to further probe these possibilities.

The findings of this study are limited in several ways. First, every methodology for assessing parenting has strengths and limitations (Holden, 2001). Although we tried to minimize some of the concerns attendant with self-report questionnaires by using spouse report questionnaires, the latter may have their own inherent limitations (e.g., they could reflect transient states about how spouses feel about each other). Likewise, peer behavior nominations have potential limitations (e.g., reputation bias; attention and recall biases). However, given their daily interaction with each other, peers may more accurately perceive salient behaviors such as aggression relative to teachers and observers in limited contexts (McNeilly-Choque et al., 1996).

Another limitation deals with our modeling of the differential construct. Our study parsimoniously treats parental differences in traditional terms as a gender-based difference, which may not be the only or most important difference worth examining. For example, one might conceptualize differential parenting in terms of general variability between the parents (regardless of which parent is significantly higher in their parenting scores). However, within our latent variable framework, it has been a sufficient methodological challenge to model ordinary (signed) latent differences, let alone absolute or squared differences. Nonetheless, future studies may be able to develop theoretical justifications (and methodological innovations) for alternative modeling approaches for dealing with differences between parents, and for disentangling how mothers' and fathers' parenting are linked to child outcomes (e.g., Stolz, Barber, \& Olsen, 2005).

Furthermore, results with a sample from only one area in mainland China (Beijing) should not be considered as representative of the diverse cultures or regions that exist within China. For example, previous research suggests that important societal differences in parenting may exist across samples from mainland China, Hong Kong, and Taiwan (Berndt, Cheung, Lau, Hau, \& Lew, 1993). However, studies conducted by other research groups in Beijing (e.g., Chen et al., 2001) and Hong Kong (e.g., Chang et al., 2004) have yielded similar findings, with aversive parenting being predictive of aggressive/disruptive child behaviors. The parents in this sample were also highly educated, and different results may be obtained with less educated populations, as suggested by Leung et al. (1998). Finally, findings obtained here may not be reflective of those that might be obtained with older children and adolescents. There is much yet to be learned about how Chinese parents may adapt their parenting as development progresses. Despite these limitations, this study represents a significant contribution to a field of rapidly expanding focus. The results provide further impetus and direction for research regarding the interplay between parenting and child aggression, both within China and across diverse cultures.

\section{References}

Bandura, A. (1973). Aggression: A social learning approach. Englewood Cliff, NJ: Prentice-Hall.

Barber, B. K. (1996). Parental psychological control: Revisiting a neglected construct. Child Development, 67, 3296-3319. 
Baumrind, D. (1971). Current patterns of parental authority. Developmental Psychology Monographs, 4(1, Part 2, pp. 1-103).

Baumrind, D. (1996). The discipline controversy revisited. Family Relations, 45, 405-414.

Bell, R. Q., \& Chapman, M. (1986). Child effects in studies using experimental or brief longitudinal approaches to socialization. Developmental Psychology, 22, 595-603.

Berndt, T. J., Cheung, P. C., Lau, S., Hau, K., \& Lew, W. J. F. (1993). Perceptions of parenting in mainland China, Taiwan, and Hong Kong: Sex differences and societal differences. Developmental Psychology, 29, 156-164.

Cabrera, N. J., Tamis-LeMonda, C. S., Bradley, R. H., Hofferth, S., \& Lamb, M. E. (2000). Fatherhood in the twenty-first century. Child Development, 71, 127-136.

Chang, L., Lansford, J. E., Schwartz, D., \& Farver, J. M. (2004). Marital quality, maternal depressed affect, harsh parenting, and child externalizing in Hong Kong Chinese families. International Journal of Behavioral Development, 28, 311-318.

Chang, L., Schwartz, D., Dodge, K., \& McBride-Chang (2003). Harsh parenting in relation to child emotion regulation and aggression. Journal of Family Psychology, 17, 598-606.

Chao, R. K. (1994). Beyond parental control and authoritarian parenting style: Understanding Chinese parenting through the cultural notion of training. Child Development, 65, 1111-1119.

Chao, R. K. (2001). Extending research on the consequences of parenting style for Chinese Americans and European Americans. Child Development, 72, 1832-1843.

Chao, R. K., \& Sue, S. (1996). Chinese parental influence and their children's school success: A paradox in the literature on parenting styles. In S. Lau (Ed.), Growing up the Chinese way (pp. 93-120). Hong Kong: The Chinese University Press.

Chao, R. K., \& Tseng, V. (2002). Parenting of Asians. In M. H. Bornstein (Ed.), Handbook of parenting. Vol. 4: Social conditions and applied parenting (pp. 59-93). Mahwah, NJ: Lawrence Erlbaum Associates.

Chen, X., Dong, Q., \& Zhou, H. (1997). Authoritarian and authoritative parenting practices and social and school performance in Chinese children. International Journal of Behavioral Development, 21, 855-873.

Chen, X., Liu, M., \& Li, D. (2000). Parental warmth, control, and indulgence and their relations to adjustment in Chinese children: A longitudinal study. Journal of Family Psychology, 14, 401-419.

Chen, X., \& Rubin, K. H. (1992). Correlates of peer acceptance in a Chinese sample of six-year-olds. International Journal of Behavioral Development, 15, 259-273.

Chen, X., Rubin, K. H., \& Li, B. (1995). Social and school adjustment of shy and aggressive children in China. Development and Psychopathology, 7, 337-349.

Chen, X., Rubin, K. H., \& Sun, Y. (1992). Social reputation and peer relationships in Chinese and Canadian children: A cross-cultural study. Child Development, 63, $1336-1343$.
Chen, X., Wang, L., Chen, H., \& Liu, M. (2002). Noncompliance and child-rearing attitudes as predictors of aggressive behavior: A longitudinal study of Chinese children. International Journal of Behavioral Development, 26, 225-233.

Chen, X., Wu, H., Chen, H., Wang, L., \& Cen, G. (2001). Parenting practices and aggressive behavior in Chinese children. Parenting: Science and Practice, 1, 159-183.

Chiu, L. H. (1987). Child-rearing attitudes of Chinese, Chinese-American, and Anglo-American mothers. International Journal of Psychology, 22, 409-419.

Coie, J. D., \& Dodge, K. A. (1998). Aggression and antisocial behavior. In W. Damon (Series Ed.) N. Eisenberg (Vol. Ed.), Handbook of child psychology, Vol. 3: Social, emotional and personality development (pp. 779-862). New York: Wiley.

Crick, N. R., Bigbee, M. A., \& Howes, C. (1996). Children's normative beliefs about aggression: How do I hurt thee? Let me count the ways. Child Development, 67, 1003-1014.

Crick, N. R., Casas, J. J., \& Mosher, M. (1997). Relational and overt aggression in preschool. Developmental Psychology, 33, 579-588.

Crick, N. R., \& Grotpeter, J. K. (1995). Relational aggression, gender, and social-psychological adjustment. Child Development, 66, 710-722.

Crick, N. R., Grotpeter, J. K., \& Bigbee, M. A. (2002). Relationally and physically aggressive children's intent attributions and feelings of distress for relational and instrumental peer provocations. Child Development, 73, $1134-1142$.

Crick, N., Werner, N. E., Casas, J. F., O'Brien, K. M., Nelson, D. A., Grotpeter, J. K., et al. (1999). Childhood aggression and gender: A new look at an old problem. In D. Bernstein (Ed.), The Nebraska symposium on motivation: Gender and motivation (Vol. 45, pp. 75-141). Lincoln, NE: University of Nebraska Press.

Darling, N., \& Steinberg, L. (1993). Parenting style as context: An integrative model. Psychological Bulletin, 113, 487-496.

Deal, J. E., Halverson, C. F., \& Wampler, K. S. (1989). Parental agreement on child-rearing orientations: Relations to parental, marital, family, and child characteristics. Child Development, 60, 1025-1034.

Deater-Deckard, K., \& Dodge, K. A. (1997). Externalizing behavior problems and discipline revisited: Nonlinear effects and variation by culture, context, and gender. Psychological Inquiry, 8, 161-175.

Dornbusch, S. M., Ritter, P. L., Leiderman, P. H., Roberts, D. F., \& Fraleigh, M. J. (1987). The relation of parenting style to adolescent school performance. Child Development, 58, 1244-1257.

Duncan, T. E., Duncan, S. C., Strycker, L. A., Li, F., \& Alpert, A. (1999). An introduction to latent variable growth curve modeling. Mahwah, NJ: Lawrence Erlbaum.

French, D. C., Jansen, E. A., \& Pidada, S. (2002). United States and Indonesian children's and adolescents' reports of relational aggression by disliked peers. Child Development, 73, 1143-1150. 
Fung, H. (1999). Becoming a moral child: The socialization of shame among young Chinese children. Ethos, 27, 180-209.

Grusec, J. E. (2002). Parental socialization and the acquisition of values. In M. H. Bornstein (Ed.), Handbook of parenting. Vol. 5: Practical issues in parenting (pp. 143167). Mahwah, NJ: Lawrence Erlbaum Associates.

Hart, C. H., DeWolf, M., Wozniak, P., \& Burts, D. C. (1992). Maternal and paternal disciplinary styles: Relations with preschoolers' playground behavioral orientations and peer status. Child Development, 63, 879-892.

Hart, C. H., Nelson, D. A., Robinson, C. C., Olsen, S. F., \& McNeilly-Choque, M. K. (1998). Overt and relational aggression in Russian nursery-school-age children: Parenting style and marital linkages. Developmental Psychology, 34, 687-697.

Hart, C. H., Nelson, D. A., Robinson, C. C., Olsen, S. F., McNeilly-Choque, M. K., Porter, C. L., et al. (2000). Russian parenting styles and family processes: Linkages with subtypes of victimization and aggression. In K. A. Kerns, J. M. Contreras, \& A. M. Neal-Barnett (Eds.), Family and peers: Linking two social worlds (pp. 47-84). Westport, CT: Praeger Publishers.

Hart, C. H., Newell, L. D., \& Olsen, S. F. (2003). Parenting skills and social-communicative competence in childhood. In J. O. Green \& B. R. Burleson (Eds.), Handbook of communication and social interaction skills (pp. 753-797). Mahwah, NJ: Erlbaum.

Hart, C. H., Yang, C., Nelson, L. J., Robinson, C. C., Olsen, J. A., Nelson, D. A., et al. (2000). Peer acceptance in early childhood and subtypes of socially withdrawn behavior in China, Russia, and the United States. International Journal of Behavioural Development, 24, 73-81.

Ho, D. Y. F. (1986). Chinese patterns of socialization: A critical review. In $\mathrm{M}$. H. Bond (Ed.), The psychology of the Chinese people (pp. 1-37). New York: Oxford University Press.

Ho, D. Y. F. (1987). Fatherhood in Chinese culture. In M. E. Lamb (Ed.), The father's role: Cross-cultural perspectives (pp. 227-245). Hillsdale, NJ: Lawrence Erlbaum Associates.

Hoffman, M. L. (1960). Power assertion by the parent and its impact on the child. Child Development, 31, 129-143.

Holden, G. W. (2001). Parenthood. In J. Touliatos, B. F. Perlmutter, \& M. A. Strauss (Eds.), Handbook of family measurement techniques, Vol. 1 (pp. 137-149.

Hsu, J. (1985). The Chinese family: Relations, problems, and therapy. In W. S. Tseng \& D. Y. H. Wu (Eds.), Chinese culture and mental health (pp. 95-112). Orlando, FL: Academic Press.

Khaleque, A., \& Rohner, R. P. (2002). Perceived parental acceptance-rejection and psychological adjustment: A meta-analysis of cross-cultural and intracultural studies. Journal of Marriage and Family, 64, 54-64.

Lansford, J. E., Chang, L., Dodge, K. A., Malone, P. S., Oburu, P., Palmérus, K., et al. (2005). Physical discipline and children's adjustment: Cultural normativeness as a moderator. Child Development, 76, 1234-1246.
Larzelere, R. E., Kuhn, B. R., \& Johnson, B. (2004). The intervention selection bias: An underrecognized confound in intervention research. Psychological Bulletin, 130, 289-303.

Lau, S., \& Cheung, P. C. (1987). Relations between Chinese adolescents' perception of parental control and organization and their perception of parental warmth. Developmental Psychology, 23, 726-729.

Lau, S., Lew, W. J. F., Hau, K., Cheung, P. C., \& Berndt, T. J. (1990). Relations among perceived parental control, warmth, indulgence, and family harmony of Chinese in mainland China. Developmental Psychology, $26,674-677$.

Lau, S., \& Yeung, P. P. W. (1996). Understanding Chinese child development: The role of culture in socialization. In S. Lau (Ed.), Growing up the Chinese way (pp. 29-44). Hong Kong: The Chinese University Press.

Leadbeater, B. J., Blatt, S. J., \& Quinlan, D. M. (1995). Gender-linked vulnerabilities to depressive symptoms, stress, and problem behaviors in adolescents. Journal of Research on Adolescence, 5, 1-29.

Leadbeater, B. J., Kuperminc, G. P., Blatt, S. J., \& Hertzog, C. (1999). A multivariate model of gender differences in adolescents' internalizing and externalizing problems. Developmental Psychology, 35, 1268-1282.

Leung, K., Lau, S., \& Lam, W. (1998). Parenting styles and academic achievement: A cross-cultural study. MerrillPalmer Quarterly, 44, 157-172.

Lindsey, E. W., \& Mize, J. (2001). Interparental agreement, parent-child responsiveness, and children's peer competence. Family Relations, 50, 348-354.

Lytton, H. (1990). Child and parent effects in boys' conduct disorder: A reinterpretation. Developmental Psychology, 26, 683-697.

Maccoby, E. E., \& Martin, J. A. (1983). Socialization in the context of the family: Parent-child interaction. In E. M. Hetherington (Ed.), P. H. Mussen (Series Ed.), Handbook of child psychology (pp. 1-102). New York: Wiley.

McLoyd, V. C., \& Smith, J. (2002). Physical discipline and behavior problems in African American, European American, and Hispanic children: Emotional support as a moderator. Journal of Marriage and the Family, 64, 40 - 53.

McNeilly-Choque, M. K., Hart, C. H., Robinson, C. C., Nelson, L. J., \& Olsen, S. F. (1996). Overt and relational aggression on the playground: Correspondence among different informants. Journal of Research in Childhood Education, 11, 47-67.

Muthén, L. K., \& Muthén, B. O. (2001). Mplus user's guide (2nd ed.). Los Angeles: Muthén \& Muthén.

Nelson, D. A., \& Crick, N. R. (2002). Parental psychological control: Implications for childhood physical and relational aggression. In B. K. Barber (Ed.), Intrusive parenting: How psychological control affects children and adolescents (pp. 168-189). Washington, DC: American Psychological Association.

Nelson, D. A., Nelson, L. J., Hart, C. H., Yang, C., \& Jin, S. (2006). Parenting and peer-group behavior in cultural context. In X. Chen, B. Schneider, \& D. French (Eds.), 
Peer relations in cultural context (pp. 213-246). New York: Cambridge University Press.

Nelson, D. A., Robinson, C. C., \& Hart, C. H. (2005). Relational and physical aggression of preschool-age children: Peer status linkages across informants. Early Education and Development, 16, 115-139.

Nelson, L. J., Hart, C. H., Wu, B., \& Olsen, S. F. (in press) Relations between Chinese mothers' parenting practices and social withdrawal in early childhood. International Journal of Behavioral Development.

Nix, R. L., Pinderhughes, E. E., Dodge, K. A., Bates, J. E., Pettit, G. S., \& McFadyen-Ketchum, S. A. (1999). The relation between mothers' hostile attribution tendencies and children's externalizing behavior problems: The mediating role of mothers' harsh discipline practices. Child Development, 70, 896-909.

Olsen, S. F., Yang, C., Hart, C. H., Robinson, C. C., Wu, P., Nelson, D. A., et al. (2002). Mothers' psychological control and preschool children's behavioral outcomes in China, Russia, and the United States. In B. K. Barber (Ed.), Intrusive parenting: How psychological control affects children and adolescents (pp. 235-262). Washington, DC: American Psychological Association.

Ostrov, J. M., Woods, K. E., Jansen, E. A., Casas, J. F., \& Crick, N. R. (2004). An observational study of delivered and received aggression, gender, and social-psychological adjustment in preschool: This white crayon doesn't work. Early Childhood Research Quarterly, 19, 355-371.

Park, J., Essex, M. J., Zahn-Waxler, C., Armstrong, J. M., Klein, M. H., \& Goldsmith, H. H. (2005). Relational and overt aggression in middle childhood: Early child and family risk factors. Early Education and Development, 16, 233-257.

Peterson, G. W., \& Hann, D. (1999). Socializing parents and children in families. In S. Steinmetz, M. Sussman, \& G. W. Peterson (Eds.), Handbook of marriage and the family (Rev. ed., pp. 327-370). New York: Plenum Press.

Polaha, J., Larzelere, R. E., Shapiro, S. K., \& Pettit, G. S. (2004). Physical discipline and child behavior problems: A study of ethnic group differences. Parenting: Science and Practice, 4, 339-360.

Porter, C. L., Hart, C. H., Yang, C., Robinson, C. C., Olsen, S., Zeng, Q., et al. (2005). A comparative study of child temperament and parenting in Beijing, China and the western United States. International Journal of Behavioral Development, 29, 541-551.

Robinson, C. C., Mandleco, B., Olsen, S. F., \& Hart, C. H. (2001). The parenting styles and dimensions questionnaire (PSDQ). In B. F. Perlmutter, J. Touliatos, \& G. W. Holden (Eds.), Handbook of family measurement techniques: Vol. 3. Instruments $\mathcal{E}$ index (pp. 319-321). Thousand Oaks, CA: Sage.

Rohner, R. P., Kean, K. J., \& Cournoyer, D. E. (1991). Effects of corporal punishment, perceived caretaker warmth, and cultural beliefs on the psychological adjustment of children in St. Kitts, West Indies. Journal of Marriage and the Family, 53, 681-693.
Rose, A. J., Swenson, L. P., \& Waller, E. M. (2004). Overt and relational aggression and perceived popularity: Developmental differences in concurrent and prospective relations. Developmental Psychology, 40, 378-387.

Rowe, D. C., Vazsonyi, A. T., \& Flannery, D. J. (1994). No more than skin deep: Ethnic and racial similarity in developmental process. Psychological Review, 101, 396-413.

Rudolph, K. D., \& Hammen, C. (1999). Age and gender as determinants of stress exposure, generation, and reactions in youngsters: A transactional perspective. Child Development, 70, 660-677.

Rudolph, K D., Hammen, C., Burge, D., Lindberg, N., Herzberg, L., \& Daley, S. E. (2000). Toward an interpersonal life-stress model of depression: The developmental contexts of stress generation. Development and Psychopathology, 12, 215-234.

Russell, A., Hart, C. H., Robinson, C. C., \& Olsen, S. F. (2003). Children's sociable and aggressive behavior with peers: A comparison of the U.S. and Australia, and contributions of temperament and parenting styles. International Journal of Behavioral Development, 27, 74-86.

Russell, A., Mize, J., \& Bissaker, K. (2002). Parent-child relationships. In P. K. Smith \& C. H. Hart (Eds.), Blackwell handbook of social development (pp. 205-222). Malden, MA: Blackwell Publishers.

Russell, A., \& Russell, G. (1994). Coparenting early schoolage children: An examination of mother-father interdependence within families. Developmental Psychology, $30,757-770$.

Sorkhabi, N. (2005). Applicability of Baumrind's parent typology to collective cultures: Analysis of cultural explanations of parent socialization effects. International Journal of Behavioral Development, 29, 552-563.

Steinberg, L., Dornbusch, S., \& Brown, B. B. (1992). Ethnic differences in adolescent achievement: An ecological perspective. American Psychologist, 47, 723-729.

Stevens, J. (1996). Applied multivariate statistics for the social sciences. Mahwah, NJ: Lawrence Erlbaum.

Stevenson, H. W., Chen, C., \& Lee, S. (1992). Chinese families. In J. L. Roopnarine \& D. B. Carter (Eds.), Parent-child socialization in diverse cultures: Advances in applied developmental psychology (pp. 17-33). Norwood, NJ: Ablex Publishing Corporation.

Stolz, H. E., Barber, B. K., \& Olsen, J. A. (2005). Toward disentangling mothering and fathering: An assessment of relative importance. Journal of Marriage and Family, 67, 1076-1092.

Widaman, K. F., \& Reise, S. P. (1997). Exploring the measurement invariance of psychological instruments: Applications in the substance use domain. In K. J. Bryant, M. Windle, \& S. G. West (Eds.), The science of prevention: Methodological advances from alcohol and substance abuse research (pp. 281-324). Washington, DC: American Psychological Association.

Winsler, A., Madigan, A. L., \& Aquilino, S. A. (2005). Correspondence between maternal and paternal parenting styles in early childhood. Early Childhood Research Quarterly, 20, 1-12. 
Wu, D. Y. H. (1981). Child abuse in Taiwan. In J. E. Korbin (Ed.), Child abuse and neglect: Cross-cultural perspectives (pp. 139-165). Los Angeles: University of California Press.

Wu, D. Y. H. (1996). Parental control: Psychocultural interpretations of Chinese patterns of socialization. In S. Lau (Ed.), Growing up the Chinese way: Chinese child and adolescent development (pp. 1-28). Hong Kong: The Chinese University Press.

Wu, P., Robinson, C. C., Yang, C., Hart, C. H., Olsen, S. F., Porter, C. L., et al. (2002). Similarities and differences in mothers' parenting of preschoolers in China and the
United States. International Journal of Behavioral Development, 26, 481-491.

Xu, Y., Farver, J. M., Zhang, Z., Zeng, Q., Yu, L., \& Cai, B. (2005). Mainland Chinese parenting styles and parentchild interaction. International Journal of Behavioral Development, 29, 524-531.

Yang, C., Hart, C. H., Nelson, D. A., Porter, C. L., Olsen, S. F., Robinson, C. C., \& Jin, S. (2004). Fathering in a Beijing, Chinese sample: Associations with boys' and girls' negative emotionality and aggression. In R. D. Day \& M. E. Lamb (Eds.), Conceptualizing and measuring father involvement (pp. 185-215). Mahwah, NJ: Erlbaum. 